It is known that $50 \% \mathrm{~N}_{2} \mathrm{O}$ and $50 \% \mathrm{O}_{2}$ mixture is a safe and efficient analgesic for parturient women. The British Oxygen Company have produced single cylinders of premixed gases containing a 50/50 gas and oxygen mixture, which would be ideal for use in midwifery if they could be relied upon to dispense a constant 50/50 mixture.

Composition changes in premixed gas and oxygen mixtures have been reported at low temperatures; for this reason an experimental investigation has been conducted into the effects of cooling upon premixed cylinders of the recommended $50 \%$ $\mathrm{N}_{2} \mathrm{O}$ and $50 \% \mathrm{O}_{2}$ mixture.

Under certain conditions of use partially filled cylinders of $50 / 50 \mathrm{~N}_{2} \mathrm{O}$ and $\mathrm{O}_{2}$ exposed to temperatures of $-8^{\circ} \mathrm{C}$. or below. undergo partial stratification of the constituent gases. The result of this could be that the last fraction of gas obtained from the cylinder contains as little as $2 \% \mathrm{O}_{2}$.

The conditions leading to this state of affairs are discussed and are thought to be unlikely to arise in practice $(P=0.0001)$. The nature of the dispensing apparatus is such as to minimize the danger. The precautions necessary to prevent stratification appear to be so elementary as to fail to constitute a barrier to the domiciliary use of $50 / 50 \mathrm{~N}_{2} \mathrm{O}$ and $\mathrm{O}_{2}$ and trouble can be completely avoided by protecting the cylinders from very low temperatures.

Nevertheless, in the event of a cylinder not being protected from frost before use, it is felt that the precautions of warming and agitating the cylinder should be taken, and would certainly prevent any dangerous deprivation of oxygen.

The help of Professor J. C. M. Browne, Mr. W. G. MacGregor, Miss C. Miller, and staff is gratefully acknowledged. We also wish to thank the British Oxygen Company Ltd. for permission to publish this paper.

\section{REFERENCES}

Central Midwives Board (1963a). Report for Year ended 31 March. - (1963b). Communication of 17 April to Medical Officers of Health of local supervising authorities.

Cole, P. V. (1964). Anaesthesia, 19, 3.

- and Nainby-Luxmore, R. C. (1962). Ibid., 17, 505.

Gale, C. W., Tunstall, M. E., and Wilton-Davies, C. C. (1964). Consumption Trials of Premixed 50/50 Nitrous Oxide/Oxygen. In preparation.

Rogers, E. H. I. (1964). Probability of Low Temperatures. Private communication, Meteorological Office.

Smith, L. P., Roulston, M., and Stratton, R. (1961). Annual Minimum Temperatures, Agriculture Memorandum XLI, Meteorological Office. Tunstall, M. E. (1961). Lancet, 2, 964.

\title{
Methyldopa in Treatment of Severe Toxaemia of Pregnancy
}

\author{
S. F. HANS,* M.D., F.R.C.S., M.R.C.o.G. ; H. KOPELMAN, $†$ M.D., M.R.C.P.
}

Brit. med. F., 1964, 1, 736-739

The chlorothiazide diuretics and hypotensive agents of all kinds have been used in the treatment of toxaemia of pregnancy. It has been suggested that the chlorothiazide group of drugs has relatively little influence on the course of the toxaemia, although its use may provide symptomatic relief from oedema (McClure Browne, 1963). The other hypotensive agents, both ganglion-blocking and adrenolytic, were more effective in the control of the hypertension, but the perinatal mortality remained unchanged from the conventional conservative treatment and the proteinuria was not improved, indicating that these hypotensive agents had no influence in the manifestations of preeclampsia (Townsend, 1963). Indeed, the bladder and bowel complications of the more effective ganglion-blocking agents made the management of some patients more difficult.

The value of methyldopa as a potent hypotensive agent relatively free from toxicity and side-effects has already been discussed in several publications (Bayliss and Harvey-Smith, 1962; Dollery and Harington, 1962 ; Hamilton and Kopelman, 1963). In the last paper reference was made to two patients in whom this drug had been used in the hypertension of pregnancy. The present paper is an account of the treatment with methyldopa of 15 patients with hypertension and toxaemia in late pregnancy.

\section{Patients Studied}

Patients with hypertension and albuminuria in the later stages of pregnancy were admitted to hospital. Some had been followed in the antenatal clinic, but a few were admitted as emergencies and had not been seen previously.

\footnotetext{
* Gynaecologist and Obstetrician, St. Margaret's Hospital, Epping, and Hertford County Hospital.

$\dagger$ Physician, St. Margaret's Hospital, Epping.
}

In the first instance they were treated with strict bed rest, sedation with phenobarbitone, low-sodium diet, and oral diuretics of the thiazide group. In some of the severely toxaemic cases there was a poor response to conservative treatment and sometimes an actual rise in the blood-pressure. In these patients this regime was continued only for 24 to 48 hours before methyldopa was given. With less severe cases a longer period of conservative treatment was tried, but when it was apparent that this was not controlling the hypertension, methyldopa was started. The 15 cases studied were therefore selected patients who had not responded to conservative treatment and were, on the whole, the more severe cases. Their ages ranged from 22 to 41 years, with an average of 33 . There were five primiparae, three with a past history of an abortion early in pregnancy, and seven multiparous patients. Six had a known history of previous toxaemia and seven were known or presumed to have had hypertension in early pregnancy (Table I). The

TABLE I.-Detalls of Patients Before Treatment

\begin{tabular}{|c|c|c|c|c|c|c|c|}
\hline $\begin{array}{l}\text { Case } \\
\text { No. }\end{array}$ & Age & $\begin{array}{c}\text { Previous } \\
\text { Preg- } \\
\text { nancy }\end{array}$ & $\begin{array}{l}\text { Previous } \\
\text { Toxaemia }\end{array}$ & $\begin{array}{l}\text { Ante- } \\
\text { natal } \\
\text { B.P. }\end{array}$ & $\begin{array}{l}\text { Onset of } \\
\text { Toxaemia } \\
\text { (Weeks) }\end{array}$ & $\begin{array}{l}\text { B.P. on } \\
\text { Admis- } \\
\text { sion* }\end{array}$ & Oedema \\
\hline $\begin{array}{r}1 \\
2 \\
3 \\
4 \\
5 \\
6 \\
7 \\
8 \\
9 \\
10 \\
11 \\
12 \\
13 \\
14 \\
15\end{array}$ & $\begin{array}{l}40 \\
31 \\
38 \\
24 \\
39 \\
22 \\
38 \\
30 \\
35 \\
41 \\
33 \\
40 \\
25 \\
28 \\
30\end{array}$ & $\begin{array}{c}\frac{1}{2} \\
2 \\
10 / 40 \\
= \\
3+\overline{12 / 40} \\
7 / 40 \\
1+14 / 40 \\
\frac{7}{14 / 40} \\
\frac{7}{2}\end{array}$ & $\begin{array}{l}1 \\
2 \\
1 \\
= \\
= \\
= \\
1 \\
1 \\
= \\
= \\
1\end{array}$ & $\begin{array}{l}130 / 90 \\
115 / 70 \\
150 / 110 \\
185 / 90 \\
160 / 100 \\
160 / 110 \\
130 / 85 \\
120 / 80 \\
- \\
140 / 90 \\
160 / 100 \\
120 / 80 \\
110 / 80 \\
140 / 100\end{array}$ & $\begin{array}{l}28 \\
34 \\
32 \\
37 \\
32 \\
33 \\
32 \\
32 \\
28 \\
34 \\
36 \\
32 \\
35 \\
36 \\
34\end{array}$ & $\begin{array}{l}240 / 170 \\
180 / 115 \\
190 / 130 \\
200 / 125 \\
200 / 110 \\
170 / 110 \\
180 / 120 \\
160 / 95 \\
165 / 110 \\
160 / 110 \\
150 / 100 \\
185 / 105 \\
175 / 120 \\
170 / 105 \\
160 / 110\end{array}$ & $\begin{array}{l} \pm \\
\pm \\
\pm \\
\pm \\
\pm \\
+ \\
+ \\
\pm \\
+ \\
\pm \\
\pm \\
\pm \\
\pm\end{array}$ \\
\hline
\end{tabular}

* Before any treatment at all. 
onset of toxaemia was first noted in the 28th to the 37th week of the pregnancy, with an average of 33 weeks. At the beginning of treatment with methyldopa the systolic pressure ranged from 160 to $240 \mathrm{~mm}$. $\mathrm{Hg}$, with an average of 188 , and the diastolic pressure ranged from 105 to $150 \mathrm{~mm}$., with an average of 119 . All the patients had albuminuria and nine had oedema.

\section{Method of Treatment}

Sedation with phenobarbitone was continued, but it was soon apparent that small doses only were required as methyldopa was sedative in the first 24 to 48 hours. An oral diuretic was used in all cases, either hydrochlorothiazide $25 \mathrm{mg}$. or bendrafluazide $5 \mathrm{mg}$. twice daily with potassium. Methyldopa was given orally in 250-mg. tablets three or four times a day. This was increased in some cases to $500 \mathrm{mg}$. three or four times a day, depending on the response in blood-pressure.

The blood-pressure was recorded four-hourly, and the pressures shown in Table II are averages of the four-hourly readings. Urinary proteins were estimated daily by the Esbach method and by the usual ward tests. Blood estimation of electrolytes and urea as well as blood counts were performed during the period of treatment and subsequently post-natally.

\section{Results of Treatment}

In all cases there was a marked improvement in the patient's general condition within 24 to 48 hours after the beginning of treatment with methyldopa. Headache, which in some cases had been severe, improved rapidly, the puffiness of the face and oedema resolved, together with a fall in the central venous pressure, as observed in the neck veins. In two of the most severe cases clinical and subsequent radiological evidence of pulmonary oedema rapidly resolved. In early cases heavy phenobarbitone sedation was continued, but later this was considerably reduced and the general well-being of the patient became very apparent.

Treatment was continued until it was evident that foetal death had occurred, or the foetus was thought to be of an easily viable age. In two patients a rash developed and the drug was omitted a few days before delivery. In later cases, when more experience had been obtained and with marked improvement in the general condition of the patient, many went to almost full term. The duration of treatment varied between 7 and 47 days, with an average of 19 days. Seven patients went into spontaneous labour, three had surgical inductions, and five had caesarean sections. No patient developed eclampsia, ante-partum accidental haemorrhage, or severe renal failure shown by oliguria or anuria (Table II).

\section{Effects of Methyldopa}

On Blood-pressure.-Fourteen of the patients showed a marked fall of both systolic and diastolic pressure generally between 24 and 48 hours from the start of using methyldopa. In a few cases it was necessary to increase the dose up to $2 \mathrm{~g}$./ day to obtain pressures within the normal range of $140 / 90$ or below (Table II, Chart). Subsequently it was found that the dose could be reduced. One patient (Case 7) did not show so satisfactory a fall in pressure, although her general condition was improved. This patient, who was rhesus-negative, had

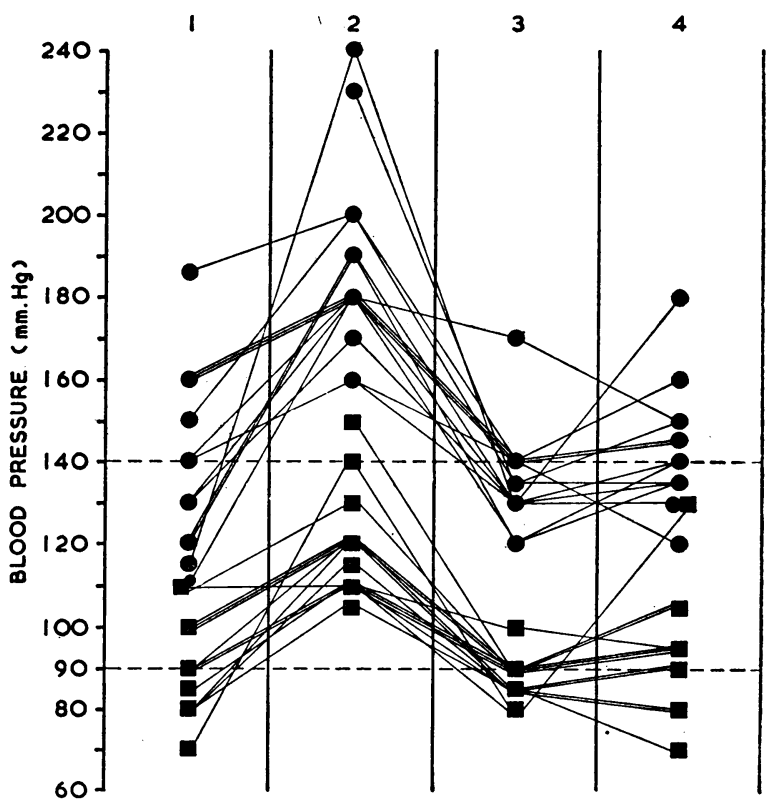

Systolic blood pressure (black circles); diastolic (black squares). The columns indicate (1) the pressure before onset of toxaemia, (2) before treatment began, (3) during treatment with methyldopa, and (4) postnatally, after methyldopa was discontinued. Each point may represent several patients' readings.

had three previous full-term pregnancies, in which two of the babies had required exchange transfusions, and subsequently an abortion at three months. A caesarean hysterectomy performed seven days after treatment was begun showed an adherent hydropic placenta and a macerated foetus.

On Proteinuria.-In all but two patients the proteinuria decreased during treatment, becoming absent in eight. In the more severe Case 13, the proteinuria persisted at the same level although the blood-pressure was well controlled. In this patient a living child weighing $6 \mathrm{lb} .4 \mathrm{oz}$. (2,385 g.) was delivered by caesarean section after 29 days of treatment. Suinsequent testing showed only an occasional trace of protein in the urine.

TABLE II.-Results of Treatment

\begin{tabular}{|c|c|c|c|c|c|c|c|c|c|c|c|c|c|}
\hline \multirow{2}{*}{$\begin{array}{l}\text { Case } \\
\text { No. }\end{array}$} & \multicolumn{3}{|c|}{ Blood-pressure } & \multicolumn{2}{|c|}{$\begin{array}{c}\text { Proteinuria } \\
\text { (g./1.) }\end{array}$} & \multicolumn{2}{|c|}{$\begin{array}{c}\text { Blood Urea } \\
\text { (mg./100 ml.) }\end{array}$} & \multirow{2}{*}{$\begin{array}{l}\text { Max. } \\
\text { Dose } \\
\text { (g. } 24 \mathrm{hr} \text {.) }\end{array}$} & \multicolumn{2}{|c|}{ Duration } & \multirow{2}{*}{$\begin{array}{l}\text { Foetal } \\
\text { Result }\end{array}$} & \multicolumn{2}{|c|}{ Birthweight } \\
\hline & Before & During & After & Before & During & Before & During & & $\underset{\text { (Days) }}{\text { Treatment }}$ & $\begin{array}{c}\text { Pregnancy } \\
\text { (Weeks) } \\
\text { Method }\end{array}$ & & lb. oz. & g. \\
\hline $\begin{array}{l}1 \\
2 \\
3 \\
4 \\
5 \\
6 \\
7 \\
8\end{array}$ & $\begin{array}{l}230 / 150 \\
170 / 110 \\
240 / 140 \\
200 / 130 \\
200 / 120 \\
180 / 120 \\
180 / 110 \\
180 / 110\end{array}$ & $\begin{array}{l}135 / 90 \\
130 / 90 \\
130 / 80 \\
140 / 90 \\
135 / 85 \\
140 / 90 \\
170 / 100 \\
140 / 90\end{array}$ & $\begin{array}{l}150 / 90 \\
140 / 95 \\
180 / 130 \\
125 / 85 \\
135 / 80 \\
145 / 95 \\
150 / 95 \\
145 / 95\end{array}$ & $\begin{array}{l}3 \cdot 5 \\
1.0 \\
\text { Trace } \\
0 \cdot 5 \\
1 \cdot 0 \\
0 \cdot 25 \\
2.5 \\
1 \cdot 0\end{array}$ & $\begin{array}{l}0 \cdot 25 \\
0 \cdot 25 \\
0 \\
0 \\
0 \\
0 \cdot 25 \\
2 \cdot 0 \\
0 \cdot 1\end{array}$ & $\begin{array}{l}35 \\
34 \\
21 \\
= \\
= \\
57\end{array}$ & $\begin{array}{l}45 \\
26 \\
29 \\
29 \\
13 \\
15 \\
60 \\
20\end{array}$ & $\begin{array}{l}1 \cdot 5 \\
2 \cdot 0 \\
1 \cdot 5 \\
0 \cdot 75 \\
1 \cdot 0 \\
0 \cdot 75 \\
2 \cdot 0 \\
2 \cdot 0\end{array}$ & $\begin{array}{r}12 \\
16 \\
47 \\
9 \\
27 \\
31 \\
7 \\
8\end{array}$ & $\begin{array}{l}30 \mathrm{~S} \\
36 \mathrm{~S} \\
38 \mathrm{C} \\
39 \mathrm{~S} \\
35 \mathrm{C} \\
39 \mathrm{I} \\
33 \mathrm{C} \\
36 \mathrm{~S}\end{array}$ & $\begin{array}{l}\text { Macerated foetus } \\
\text { Living } \\
\quad \text { " } \\
\text { ", A.P.H. } \\
\text { Hydrops foetus } \\
\text { Foetal death } \\
\text { obstetric }\end{array}$ & $\begin{array}{rr}3 & 12 \\
4 & 8 \\
7 & 0 \\
3 & 12 \\
7 & 5 \\
5 & 12\end{array}$ & $\begin{array}{l}1,700 \\
2,040 \\
3,175 \\
1,700 \\
3,315 \\
2,610\end{array}$ \\
\hline $\begin{array}{r}9 \\
10 \\
11 \\
12 \\
13 \\
14 \\
15\end{array}$ & $\begin{array}{l}190 / 115 \\
160 / 110 \\
160 / 110 \\
180 / 110 \\
190 / 120 \\
180 / 105 \\
180 / 120\end{array}$ & $\begin{array}{l}120 / 85 \\
140 / 85 \\
130 / 80 \\
140 / 90 \\
130 / 85 \\
130 / 85 \\
120 / 90\end{array}$ & $\begin{array}{l}130 / 90 \\
120 / 70 \\
120 / 95 \\
160 / 105 \\
135 / 95 \\
130 / 80 \\
140 / 100\end{array}$ & $\begin{array}{c}2.5 \\
\text { Trace } \\
1.0 \\
0.5 \\
1.0 \\
\text { Trace } \\
0.5\end{array}$ & $\begin{array}{l}0 \cdot 25 \\
0 \\
0 \\
0 \\
1 \cdot 0 \\
0 \\
0\end{array}$ & $\begin{array}{l}\frac{52}{-} \\
\overline{33} \\
28\end{array}$ & $\begin{array}{l}61 \\
26 \\
22 \\
19 \\
68 \\
29 \\
15\end{array}$ & $\begin{array}{l}2 \cdot 0 \\
0 \cdot 75 \\
0 \cdot 75 \\
0.75 \\
1.5 \\
0.75 \\
0 \cdot 75\end{array}$ & $\begin{array}{r}12 \\
11 \\
17 \\
23 \\
29 \\
9 \\
28\end{array}$ & $\begin{array}{l}30 \mathrm{~S} \\
37 \mathrm{~S} \\
40 \mathrm{C} \\
40 \mathrm{I} \\
39 \mathrm{C} \\
39 \mathrm{~S} \\
39 \mathrm{I}\end{array}$ & $\begin{array}{l}\text { Foetal death } \\
\text { Living } \\
\text {," } \\
\text { ", } \\
\text { ", } \\
\text { ", }\end{array}$ & $\begin{array}{rr}7 & 15 \\
9 & 6 \\
9 & 10 \\
6 & 4 \\
7 & 8 \\
7 & 8\end{array}$ & $\begin{array}{l}3,570 \\
4,250 \\
4,365 \\
2,385 \\
3,400 \\
3,400\end{array}$ \\
\hline
\end{tabular}


On Blood Urea.-Four patients showed a rise of blood urea to above normal levels during treatment. Only two of these (Cases 7 and 9) had a raised value when first seen. All returned to normal after parturition. Three of these patients were delivered of a dead foetus at the 29th week (Case 1), 33rd week (Case 7), and the 30th week (Case 9). The remaining patient (Case 13), who had a persistent albuminuria, was delivered of a normal living infant. In this instance the placenta showed an area of infarction $2.5 \mathrm{~cm}$. in diameter.

\section{Complications}

Apart from the sedative effect of methyldopa during the first 24 to 48 hours, the only complications seen were in two patients with skin rashes. Case 8 developed a rash on the arms and legs which became vesicular, and subsequently the vesicles became confluent. All drugs, which included the thiazides, methyldopa, and phenobarbitone, were stopped. Subsequently the lesions were thought to be due to herpes gestationis rather than to drugs, and cleared rapidly after parturition. Case 13 developed a maculopapular rash on the face and arms which started after 26 days of treatment with methyldopa. She was also on thiazide diuretics and phenobarbitone. The rash responded to treatment with an antihistamine drug.

Apart from these no other complications were noted.

\section{Foetal Results}

Early foetal death occurred in three cases. These included the rhesus-negative patient (Case 7) previously referred to, in whose case there was some doubt if the foetal heart could be heard at the beginning of treatment. In Cases 1 and 9 foetal death occurred during the first week of treatment. In Case 9 a careful examination of the placenta was made. Dr. Ivy Tuck reported it as being small and thin, weighing only $176 \mathrm{~g}$. Histology showed progressive infarction ranging in age from several weeks to the time of death, approximately $70 \%$ of the placental tissue being so affected. This patient attended the antenatal clinic four weeks prior to admission for toxaemia, when her blood-pressure was $120 / 80$ and there was no proteinuria.

One other foetal death occurred during spontaneous delivery at 36 weeks (Case 8). During the second stage foetal distress was noted and the baby was delivered by forceps. A normal 5 lb. 12 oz. $(2,610$ g.) baby was found to be dead, with the cord tightly wrapped four times around its neck. This was regarded as an obstetric death.

All other babies were fit and well and gave no abnormal trouble with respiration at birth nor subsequently with feeding or bowels.

\section{Follow-up of Patients}

The follow-up varied from some months to a short time after leaving hospital. One patient (Case 1) required further treatment with methyldopa during the post-partum period. She is the only patient who showed retinopathy (grade II to III) at the beginning of treatment. This resolved during treatment, but after parturition the blood-pressure rose and the retinopathy returned. Subsequently good control has been obtained with methyldopa.

One patient (Case 3) has shown a severe rise in blood-pressure, and a non-functioning kidney has been demonstrated in intravenous pyelography. Further investigations are being made.

Six patients have still slightly raised pressures, but they have been followed for only a short time.

\section{Discussion}

It is generally agreed that the main value of the chlorothiazide diuretics in the treatment of pre-eclamptic toxaemia is on the oedema, but the effect on the blood-pressure is less certain. Thus Assali et al. (1958) found no true hypotensive action, and Landesman $\epsilon t$ al. (1959) observed some blood-pressure fall only in uncomplicated chronic hypertensive patients, but a negligible change when acute hypertensive processes such as pre-eclampsia were present. However, Tennent and Leslie (1960) found that a proportion of patients with pre-eclamptic toxaemia did show a significant fall in blood-pressure on these drugs. The patients in our series had received these diuretics for a short time and were selected for treatment with methyldopa because they did not show any significant fall in blood-pressure.

In 14 of the 15 patients so treated a very significant fall in blood-pressure was obtained in 24 to 48 hours, and this was accompanied by a marked improvement in the general wellbeing of the patients. The dose required was relatively small and the side-effects were minimal ; the one definite drug rash may have been produced by sensitivity to other drugs given at the same time. However, the group studied is small in number and watch must be kept for other toxic manifestations which have been discussed by Hamilton and Kopelman (1963). This is in contrast to the use of the ganglion-blocking hypotensive drugs, where the side-effects on the patient and the foetus may be considerable (Agar et al., 1958).

The proteinuria in all but two cases was diminished under treatment with methyldopa, and again this is in contrast to treatment with ganglion-blocking agents. Townsend (1963) states that in his patients treated with hexamethonium, although this had a hypotensive action, no diminution in proteinurea occurred.

No attempt has been made to compare the foetal death rate in this series with that in groups undergoing other forms of treatment. It does seem that in severe toxaemia in early pregnancy ( 28 weeks) the placenta is already so affected that foetal death may be inevitable by the time symptoms and signs of the toxaemia develop and treatment can be started. In the present series four patients exhibited abnormally high blood ureas, and three of these were such cases. Although Riedel (1963a) states that a blood urea of $40 \mathrm{mg}$. $/ 100 \mathrm{ml}$. or more may indicate a severe toxaemia and possibly termination of pregnancy, one patient with a rising blood urea above this value was treated with methyldopa for four weeks and a living 6-1b. $(2,720$-g.) baby was born by caesarean section. However, the rise in the blood urea occurred later in the pregnancy, the 35 th week, and not in the 28th as in the first three patients. The main value of this treatment is in allowing the pregnancy to continue to a time when the foetus has a much better chance of survival without undue risk to the mother. It has been shown that the chance of survival of babies up to 34 weeks of gestation was about $50 \%$ (Riedel, 1963b). Nine patients, excluding the three with early foetal deaths, were 34 weeks or under at the beginning of treatment and all but one had a living normal baby. The one exception was thought to be due to an obstetric death of the baby.

We have no experience of the drug in early pregnancy complicated by severe existing hypertension. Dr. Michael Hamilton (personal communication) has successfully treated one such patient to a satisfactory conclusion with a normal healthy baby and without maternal deterioration. We have begun treatment on one such patient, but it is too early to comment on progress. The effect of the drug on the young human foetus is not known, but there is some experimental evidence to show that no adverse effect is produced in the rat's foetus (West, 1962), although from similar experiments it appears that reserpine and chlorpromazine may be harmful.

The exact mode of action of methyldopa is not known. Both a peripheral action on sympathetic nerve endings (Oates et al.s 
1960) and a central effect (Gillespie et al., 1962) may play some part. Agar et al. (1958) discussed the underlying theories of pre-eclamptic hypertension production in view of mecamylamine and the ganglion-blocking hypotensive agents being ineffectual in controlling this condition. Recently, Senior et al. (1963) have suggested that 5-hydroxytryptamine (serotonin) may have some role in the production of toxaemia of pregnancy and that antagonists of this substance may be of value in treatment. It is of interest that methyldopa interferes with the formation of serotonin in the body (Oates et al., 1960).

\section{Summary}

Methyldopa and the chlorothiazide diuretics have been used in 15 patients with severe pre-eclamptic toxaemia. All but one showed a marked and satisfactory fall in blood-pressure, a diminution in proteinuria, and improvement in well-being.

The foetus died early in treatment in three patients. All three had severe toxaemia occurring early in the third trimester and showed blood ureas above normal-one of them had the unsuccessful blood-pressure response. The other patients were able to continue with the pregnancies and all were delivered of healthy normal babies except one baby who died of an obstetric cause.

The dose of methyldopa was relatively small and the only complication was a drug rash, but other drugs were being given at the same time. However, the number of patients was small and other side-effects may occur. No deterioration has been noted in following the condition of these patients.

We should like to thank Mr. Alan Brews for permission to publish his cases.

\section{REFERENCES}

Agar, H., Barrett, C. T. H., and Exley, K. A. (1958). 7. Obstet. Gynaec. Brit. Cwlth, 65, 378.

Assali, N. S., Judd, L., Mondz, N., and Dasgupta, K. (1958). F. Lab. clin. Med., 52, 423.

Bayliss, R. I. S., and Harvey-Smith, E. A. (1962). Lancet, 1, 763.

Dollery, C. T., and Harington, M. (1962). Ibid., 1, 759.

Gillespie, L., Oates, J. A., Crout, J. R., and Sjoerdsma, A. (1962). Circulation, 25, 281.

Hamilton, M., and Kopelman, H. (1963). Brit. med. F., 1, 151.

Landesman, R., Ollstein, R. N., and Quinton, K. J. (1959). N.Y. St. F. Med., 59, 66.

McClure Browne, J. C. (1963). In Modern Trends in Obstetrics, edited by R. J. Kellar, p. 1. Butterworth, London.

Oates, J. A., Gillespie, L., Undenfriend, S., and Sjoerdsma, A. (1960). Science, 131, 1890 .

Riedel, J. A. (1963a). F. Obstet. Gynaec. Brit. Cwlth, 70, 456.

- (1963b). Ibid., 70, 145.

Senior, J. B., Fahim, I., Sullivan, F. M., Robson, J. M. (1963). Lancet, 2, 553 .

Tennent, R. A., and Leslie, D. W. (1960). Scot. med. 7., 5, 113.

Townsend, S. L. (1963). In Modern Trends in Obstetrics, edited by R. J. Kellar, p. 15. Butterworth, London.

West, G. B. (1962). F. Pharm. Pharmacol., 14, 828.

\title{
Controlled Trial of Chlorothiazide in Treatment of Early Pre-eclampsia
}

\author{
D. N. MENZIES,* M.B., CH.B., F.R.C.S.ED., M.R.C.o.G.
}

Brit. med. F., 1964, 1, 739-742

Pre-eclampsia remains a common complication of pregnancy in this country. Although the foetal wastage appears to be slightly less now than ten years ago, the figures from the National Birthday Trust Perinatal Mortality Survey show that in pregnancies resulting in stillbirth or neonatal death there is still a raised incidence of pre-eclampsia (D. G. Bonham, personal communication, 1963). It is also one of the three most common features of the history where the mother has died ; $18 \%$ of maternal deaths are associated with pre-eclampsia (Ministry of Health, 1963).

In spite of the importance of the condition the cause remains obscure, and treatment, although relatively successful, is still largely empirical. Hypotensive drugs may have value if given early in pregnancy, but this treatment is possible only for those women who show early hypertension. In cases of non-toxaemic hypertension reserpine seems to have a place but does not reduce foetal loss (Landesman and Ollstein, 1958). In true preeclampsia hypotensive drugs can only be given late and the results are disappointing. A large number of clinicians still rely on prescribing a sedative and advising bed rest, and of these two methods rest in bed is the least empirical. It is known that the myometrial blood-flow is decreased in preeclampsia (Morris et al., 1955 ; Dixon et al., 1963), but with rest this is greatly improved (Morris et al., 1956). Rest also results in an increased urinary volume and sodium excretion (Thomas, 1957, 1959). Unfortunately, such a line of treatment * First Assistant, Obstetric Unit, University College Hospital Medical
School, London. necessitates the early admission of large numbers of women to hospital. In most units such a policy leads to overcrowding in the antenatal wards. From the patient's point of view the prolonged separation from husband and family is an intolerable strain. Many of these women prefer to decline admission and accept the risk of remaining an out-patient.

At University College Hospital, London, the demand for antenatal beds is never satisfied. In 19501,270 patients were delivered and the foetal mortality associated with pre-eclampsia (excluding essential hypertension) was $4.5 \%$. This figure was achieved by admitting, for periods ranging as high as 38 days, 48 of 66 mothers suffering from the complication. Furthermore, of the 57 surgical inductions in that year, 37 were for hypertension in pregnancy (Musgrove, 1950). Greater attention is now paid to minor signs of pre-eclampsia ; this has resulted in a greater number of diagnoses over latter years. In spite of these new diagnostic criteria there has been little improvement in the perinatal mortality. During 1960 out of a total of 1,358 delivered patients $223(16.4 \%)$ were diagnosed as having pre-eclampsia. The perinatal mortality was $3.14 \%$. To produce this reduction of less than $1.4 \%$ all but 48 were admitted to hospital-that is, 175 women spent up to a maximum of 90 days in hospital (Woolf, 1960). Eighty-four were in hospital for up to a week before delivery, and 35 for more than a week but not more than two weeks. Prolonged treatment was required by 56,38 of them remaining in the ward until the third week and 18 requiring more than a month in hospital. Of all these women 114 were treated by induction. This in all amounts to a hospital-bed occupancy of 2,480 days per year or a ward 